\title{
Synthesis of Hydroxybenzodiazepines with Potential Antioxidant and Antifungal Action
}

\author{
Elizeu C. Caiana, ${ }^{a}$ Bruno O. de Veras, ${ }^{b}$ Antônia L. de Souza ${ }^{a}$ and Neide Queiroz ${ }^{\oplus *, a}$ \\ ${ }^{a}$ Departamento de Química, Universidade Federal da Paraíba, 58051-900 João Pessoa-PB, Brazil \\ ${ }^{b}$ Departamento de Medicina Tropical, Universidade Federal de Pernambuco, 50670-901 Recife-PE, Brazil
}

\begin{abstract}
Benzodiazepines derivatives are nitrogen heterocyclic compounds that have various industrial, synthetic, and medicinal applications. Therefore, its potential fully justifies every effort towards the improvement of new, selective, and competent production of these heterocyclic compounds. The novelty of this study encompasses the synthesis of new hydroxylated analogs of 1,5-benzodiazepine together with the evaluation of their biological potential as antioxidants and antifungals candidates. Additionally, the reported antifungal activity against fungi of the Sporothrix schenckii complex inaugurates an unprecedented property for this class of compounds. The results of biological activities assays suggest that the novel 2,7-dimethyl-2,4-bis(4-hydroxyphenyl)-2,3-dihydro$1 H-1,5$-benzodiazepine possesses a high antifungal activity against all fungal strains evaluated of the Sporothrix genus and outstanding total antioxidant capacity. Besides, in silico studies have evidenced that the hydroxylated derivatives have the best aqueous solubility and cell permeability profile, which makes them superior in comparison with the commercial antifungal itraconazole, a drug commonly used in the treatment of sporotrichosis.
\end{abstract}

Keywords: biological activities, solvent effect, ADME properties, Sporothrix

\section{Introduction}

The heterocyclic compounds are an essential class of molecules with a wide spectrum of pharmacological properties. It includes 1,4- and 1,5-benzodiazepines, which are of fundamental importance due to having a broad structural and pharmacological potential. ${ }^{1-4}$ Some examples of benzodiazepines commercially available as psychotherapeutic agents over the years by pharmaceutical laboratories are illustrated in Figure 1.

In addition to the well-established applications of benzodiazepines, other pharmacological activities include antimicrobial, ${ }^{5,6}$ anti-inflammatory, ${ }^{7-9}$ antioxidant, ${ }^{6,9-11}$ analgesic, ${ }^{7,11}$ anticancer, ${ }^{12,13}$ anthelmintic, ${ }^{14}$ leishmanicidal, ${ }^{15}$ antimalarial, ${ }^{16}$ antiviral ${ }^{17}$ and anti-HIV (human immunodeficiency virus) ${ }^{18}$ Furthermore, these compounds have found great use as intermediates in obtaining other fused ring heterocycles. ${ }^{19}$

It is known that the structural versatility of $N$-heterocyclic compounds allows the potentiation of the pharmacological properties of drugs or drug candidates. Therefore, incorporation of polar (e.g., hydroxyl) and non-polar (e.g., alkyl) groups enables the optimization of physical-

*e-mail: neide@quimica.ufpb.br chemical parameters of the molecule, such as lipophilicity, solubility, number of donors and acceptors of hydrogen bonding and others, resulting in increased interactions with biomacromolecules and, therefore, in the intensification of biological activity. ${ }^{20,21}$ Consequently, this class continues to be explored in order to obtain new leading molecules for drug development that are more efficient for the treatment of the most varied diseases.

Previous work $^{3,22,23}$ regarding the synthesis of 1,5-benzodiazepines is via cyclocondensation reactions of 1,2-diaminobenzene with ketones or $\alpha, \beta$-unsaturated carbonyl compounds, making use of different catalysts. In the field of green chemistry, many studies ${ }^{24}$ have investigated the use of organic acids, for the development of sustainable protocols. In some of them, the use of techniques such as microwaves ${ }^{25,26}$ and ultrasound ${ }^{27}$ have also been described to achieve higher yields in shorter reaction times.

About the antioxidant activity of benzodiazepines, in general, it has been more evident in those containing a phenolic hydroxyl group in its structure, as for example, 6-hydroxy-2-methyl-2,4-bis(4-chlorophenyl)-2,3-dihydro$1 H$-1,5-benzodiazepine. ${ }^{10}$ The conjugated $\pi$ systems favor hydrogen transfer of hydroxyl group due stabilization of the formed radical. ${ }^{28}$ So, these molecules act as antioxidant 
<smiles>Cc1nnc2n1-c1ccc(Cl)cc1C(c1ccccc1)=NC2</smiles>

Alprazolam<smiles>CN1C(=O)CC(=O)N(c2ccccc2)c2cc(Cl)ccc21</smiles>

Clobazam<smiles>O=C1CN=C(c2ccccn2)c2cc(Br)ccc2N1</smiles>

Bromazepam<smiles>CN1C(=O)CC(=O)N(c2ccccc2)c2cc(C(F)(F)F)ccc21</smiles>

Triflubazam<smiles>CN1C(=O)CN=C(c2ccccc2F)c2cc([N+](=O)[O-])ccc21</smiles>

Flunitrazepam<smiles>CCOC(=O)N1CCC(=O)N(c2ccccc2)c2cc(Cl)ccc21</smiles>

Arfendazam

Figure 1. Structures of some of the most important benzodiazepine derivatives commercially available.

preventing the formation of radicals that contribute to the development of various pathologies. ${ }^{29-31}$

Fungal infections as well as high levels of free radicals can cause serious threats to human health. This means that development of novel antifungal agents is important because fungi, like bacteria, can develop drug resistance, making treatment of fungal infections less effective. The antifungal drugs treat fungal infections by killing or stopping the growth of dangerous fungi in the body. Sporotrichosis appears among the main fungal infections, which represents the subcutaneous mycosis with greater predominance in regions of tropical and subtropical climate. This infection that affects humans and cats is caused by the dimorphic fungus Sporothrix schenckii which has a worldwide distribution. ${ }^{32-34}$ The antifungal agents conventionally used in the treatment of different manifestations of sporotrichosis are itraconazole, amphotericin B and potassium iodide. However, these drugs have presented several disadvantages regarding their clinical applications, such as the occurrence of serious side effects and the development of drug resistance. ${ }^{32,33,35}$ Furthermore, it is desirable to synthesize drugs that might be more effective in the treatment of sporotrichosis. As far as we know there is no report on the application of benzodiazepine derivatives to inhibit strains that cause sporotrichosis.

The literature ${ }^{36}$ reports the antimicrobial potential of a series of derivatives 1,5-benzodiazepines, with an emphasis on better $p$-hydroxylated compounds performance in inhibiting bacterial and fungal strains. Other studies ${ }^{5,37}$ have reported that the incorporation of lipophilic groups (ester) in the benzodiazepine nucleus leads to an improvement in antimicrobial properties, due to the increased penetration of compounds in the cell membrane of microorganisms.

In view of this, the work in question aimed to synthesize 2,3-dihydro-1 $H$-1,5-benzodiazepine, and its hydroxylated and alkylated analogues. Additionally, the solvent effects on reaction yield, and the in vitro antifungal and antioxidant activities were evaluated, as well as in silico studies, which were used for the theoretical determination of the parameters indicating the oral bioavailability of these compounds. Since, for a compound to be considered as a new drug candidate, it is essential to assess the physicalchemical parameters associated with its pharmacokinetic properties of absorption, distribution, metabolism, and excretion (ADME). ${ }^{38}$ Thus, it is worth noting that the novelty of this study encompasses the synthesis of new hydroxylated analogs together with the evaluation of their biological potential as antioxidants and antifungals candidates.

\section{Experimental}

\section{General information}

All reagents and solvents were used as purchased from Sigma-Aldrich (São Paulo, Brazil) without further 
purification. Uncorrected melting points were determined in a Fisatom Mod.431D apparatus. Analytical TLC (thin layer chromatography) was performed using silica gel 60 F254 aluminium sheets (SiliCycle Inc., Quebec, Canada).

Infrared spectra were recorded on a Shimadzu Fourier transform infrared spectrophotometer (FTIR, IRPrestige-21 model) in the range $400-4000 \mathrm{~cm}^{-1}$, using $\mathrm{KBr}$ pellets. ${ }^{1} \mathrm{H}$ and ${ }^{13} \mathrm{C}$ nuclear magnetic resonance (NMR) spectra were acquired in a Varian VNMRS $500\left(500 \mathrm{MHz}\right.$ for ${ }^{1} \mathrm{H}$ and $125 \mathrm{MHz}$ for $\left.{ }^{13} \mathrm{C}\right)$ or Bruker Ascend $400\left(400 \mathrm{MHz}\right.$ for ${ }^{1} \mathrm{H}$ and $100 \mathrm{MHz}$ for ${ }^{13} \mathrm{C}$ ) spectrometers. Coupling constants $(J)$ are reported in hertz, and chemical shifts $(\delta)$ are reported in parts per million (ppm) relative to $\mathrm{CDCl}_{3}\left(7.26 \mathrm{ppm}\right.$ for ${ }^{1} \mathrm{H}$ and $77.0 \mathrm{ppm}$ for ${ }^{13} \mathrm{C}$ ) and dimethyl sulfoxide (DMSO- $d_{6}$ ) (2.49 ppm for ${ }^{1} \mathrm{H}$ and $39.5 \mathrm{ppm}$ for ${ }^{13} \mathrm{C}$ ). Tetramethylsilane (TMS) was used as internal standard.

High-resolution mass spectrometry spectra (HRESIMS) were performed with a micrOTOF-Q II (Bruker Daltonics) mass spectrometer. The mass spectrometer was operating in the positive ion mode with mass range of $m / z$ 50-1000. The standard electrospray ion (ESI) source was used to generate the ions. The mass spectrum were acquired by direct sample injection $\left(180 \mu \mathrm{L} \mathrm{min}^{-1}\right)$ with nebulization temperature of $180^{\circ} \mathrm{C}$.

General procedure for the synthesis of 2,3-dihydro$1 H$-1,5-benzodiazepines (3a-3f)

To a mixture of $o$-phenylenediamine $\mathbf{1 a}-\mathbf{1 b}(1.0 \mathrm{mmol})$ and acetophenone or hydroxyacetophenone $\mathbf{2 a - 2} \mathbf{c}(2.2 \mathrm{mmol})$ in ethanol $(3 \mathrm{~mL})$, trifluoroacetic acid (TFA, $0.1 \mathrm{mmol}$, $10 \mathrm{~mol} \%$ ) was added (Scheme 1). The reaction mixture was stirred at ambient temperature for an appropriate time (Table 1). Compounds formation was accompanied by TLC analysis using 3:7 hexane/EtOAc (3a and 3d) and 1:1 hexane/ EtOAc (3b, 3c, 3e and $\mathbf{3 f})$ as the eluent. After complete reaction, as indicated by TLC, the reaction mixture was poured into an ice bath and basified with $5 \%(\mathrm{~m} / \mathrm{v})$ ammonia solution. The resulting solid was collected under reduced pressure at $500 \mathrm{mmHg}$, washed with cold water to neutral
$\mathrm{pH}$, and dried at room temperature. When was necessary, the solid was purified by column chromatography $\left(\mathrm{SiO}_{2}\right.$, hexane/EtOAc) to afford product 3 .

2-Methyl-2,4-diphenyl-2,3-dihydro-1 $\mathrm{H}$-1,5-benzodiazepine (3a)

Yellow solid; mp 104-107 ${ }^{\circ} \mathrm{C}$; IR (KBr) $\bar{v} / \mathrm{cm}^{-1} 3277$, 3061, 2972, 2920, 1632, 1595, 1445, 1329; ${ }^{1} \mathrm{H}$ NMR $\left(400 \mathrm{MHz}, \mathrm{CDCl}_{3}\right) \delta 1.77\left(\mathrm{~s}, 3 \mathrm{H}, \mathrm{CH}_{3}\right), 2.99(\mathrm{~d}, 1 \mathrm{H}$, $J 13.2 \mathrm{~Hz}, \mathrm{CH}_{2}$ ), 3.17 (d, $1 \mathrm{H}, J 13.2 \mathrm{~Hz}, \mathrm{CH}_{2}$ ), 3.56 (br s, 1H, NH), 6.86 (dd, 1H, J 7.6, 1.5 Hz, Ar-H), 7.02-7.14 (m, 2H, Ar-H), 7.15-7.35 (m, 6H, Ph-H), 7.38 (dd, 1H, J 7.5, $1.7 \mathrm{~Hz}, \mathrm{Ar}-\mathrm{H}), 7.57-7.63$ (m, 4H, Ph-H); ${ }^{13} \mathrm{C}$ NMR $\left(100 \mathrm{MHz}, \mathrm{CDCl}_{3}\right) \delta 30.1,43.3,73.9,121.6,121.8,125.6$, 126.7, 127.2, 127.4, 128.2, 128.5, 128.7, 130.1, 138.3, 139.3, 147.6, 168.2; HRMS (ESI-time of flight (TOF)MS) $m / z$, calcd. for $\mathrm{C}_{22} \mathrm{H}_{21} \mathrm{~N}_{2}[\mathrm{M}+\mathrm{H}]^{+}: 313.1699$, found: 313.1714 .

2-Methyl-2,4-bis (3-hydroxyphenyl)-2,3-dihydro$1 \mathrm{H}-1,5$-benzodiazepine (3b)

Yellow solid; mp 136- $139^{\circ} \mathrm{C}$; IR $(\mathrm{KBr}) \bar{v} / \mathrm{cm}^{-1} 3335$, 3242, 3055, 2963, 2916, 1605, 1582, 1454, 1323, 1254; ${ }^{1} \mathrm{H}$ NMR $\left(500 \mathrm{MHz}\right.$, DMSO- $\left.d_{6}\right) \delta 1.59$ (s, 3H, $\left.\mathrm{CH}_{3}\right), 2.83$ (d, $\left.1 \mathrm{H}, J 13.6 \mathrm{~Hz}, \mathrm{CH}_{2}\right), 3.14\left(\mathrm{~d}, 1 \mathrm{H}, J 13.6 \mathrm{~Hz}, \mathrm{CH}_{2}\right), 5.60$ (br s, $1 \mathrm{H}, \mathrm{NH}$ ), 6.53 (dd, 1H, J 7.9, $2.3 \mathrm{~Hz}, \mathrm{Ar}-\mathrm{H}$ ), 6.72-6.78 (m, 1H, Ar-H), 6.82-6.88 (m, 1H, Ar-H), 6.92-7.13 (m, 8H, $7 \mathrm{PhHOH}$ and $1 \mathrm{H}, \mathrm{Ar}-\mathrm{H}), 7.28$ (s, $1 \mathrm{H}, \mathrm{Ph} H \mathrm{OH}), 9.16(\mathrm{~s}, 1 \mathrm{H}$, $\mathrm{OH}), 9.36(\mathrm{~s}, 1 \mathrm{H}, \mathrm{OH}) ;{ }^{13} \mathrm{C}$ NMR (125 MHz, DMSO- $\left.d_{6}\right) \delta$ 30.6, 42.6, 71.2, 112.8, 113.1, 113.3, 116.1, 116.8, 118.1, $119.5,121.0,126.0,128.7,128.8,128.8,138.1,139.6,140.9$, 149.9, 156.8, 157.0, 165.4; HRMS (ESI-TOF-MS) $\mathrm{m} / \mathrm{z}$, calcd. for $\mathrm{C}_{22} \mathrm{H}_{21} \mathrm{~N}_{2} \mathrm{O}_{2}[\mathrm{M}+\mathrm{H}]^{+}$: 345.1598, found: 345.1601 .

2-Methyl-2,4-bis(4-hydroxyphenyl)-2,3-dihydro$1 \mathrm{H}$-1,5-benzodiazepine (3c)

Yellow solid; mp 205-208 ${ }^{\circ} \mathrm{C}$; IR (KBr) $\bar{v} / \mathrm{cm}^{-1} 3341$, 3181, 3030, 2968, 2924, 1612, 1599, 1454, 1331, 1240; ${ }^{1} \mathrm{H}$ NMR $\left(500 \mathrm{MHz}, \mathrm{DMSO}-d_{6}\right) \delta 1.58\left(\mathrm{~s}, 3 \mathrm{H}, \mathrm{CH}_{3}\right), 2.79$ (d, $1 \mathrm{H}, J 13.4 \mathrm{~Hz}, \mathrm{CH}_{2}$ ), $3.04\left(\mathrm{~d}, 1 \mathrm{H}, J 13.3 \mathrm{~Hz}, \mathrm{CH}_{2}\right), 5.31$

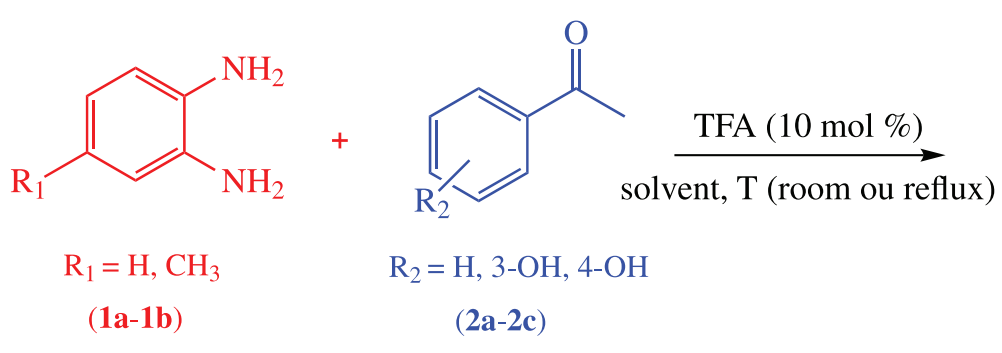

(1a-1b)
$(2 \mathbf{a}-\mathbf{2 c})$

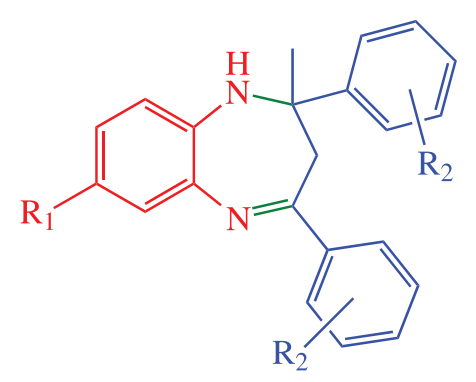

6 examples (3a-3f)

Scheme 1. Synthesis of 1,5-benzodiazepines via condensation of $o$-phenylenediamines and ketones. 
Table 1. Yields of 1,5-benzodiazepines using methanol and ethanol as solvent in the cyclocondensation catalyzed by trifluoroacetic acid (TFA)

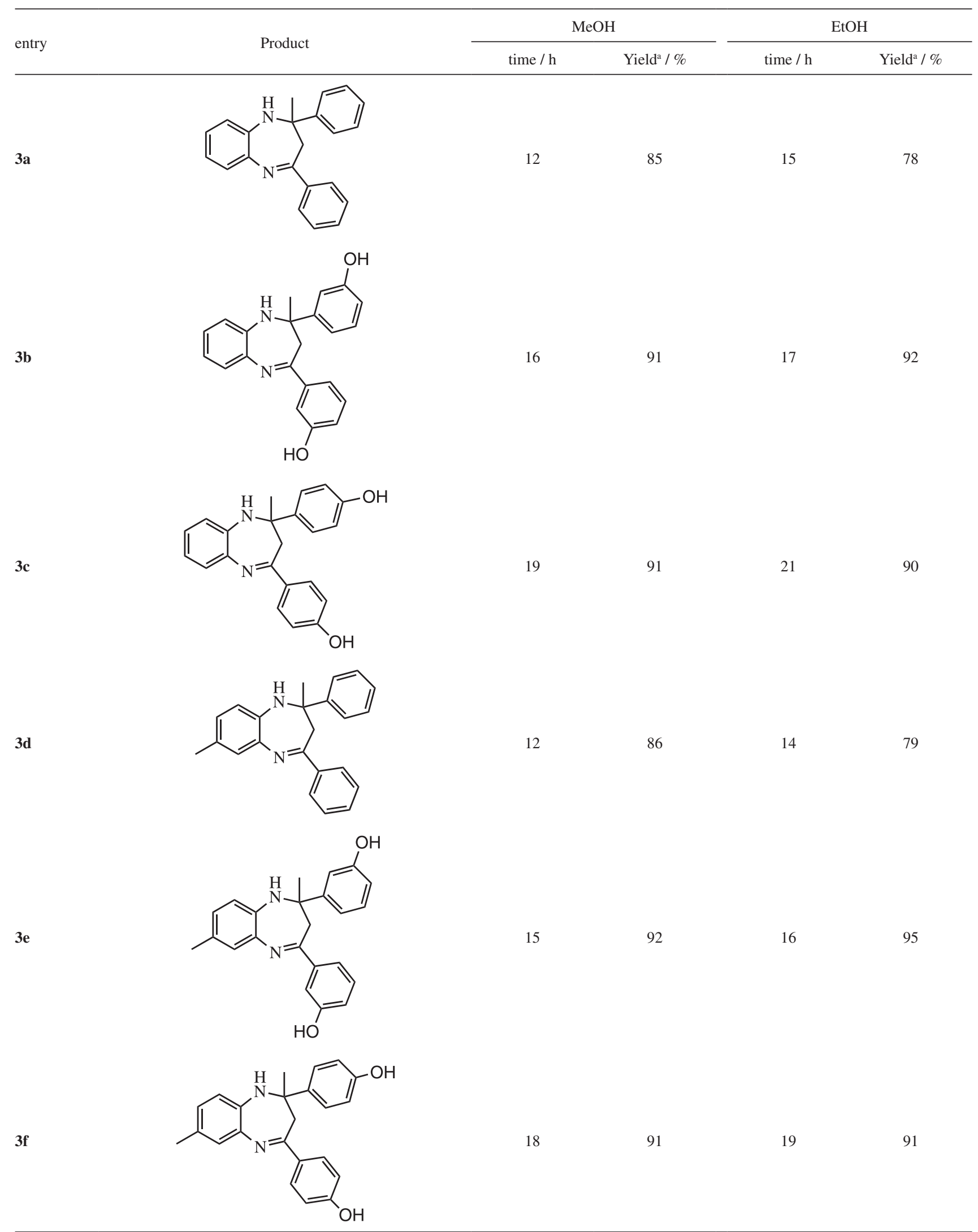

asolated yield. MeOH: methanol; EtOH: ethanol. 
(br s, 1H, NH), 6.61 (d, 2H, J $8.8 \mathrm{~Hz}, \mathrm{PhHOH}), 6.66$ (d, $2 \mathrm{H}, J 8.8 \mathrm{~Hz}, \mathrm{PhHOH}), 6.82-6.87$ (m, 1H, Ar-H), 6.93-6.99 (m, 2H, Ar-H), 7.06 (d, 1H, J 7.2 Hz, Ar-H), 7.36 (d, 2H, $J 8.8 \mathrm{~Hz}, \mathrm{PhHOH}), 7.59$ (d, 2H, J $8.8 \mathrm{~Hz}, \mathrm{PhHOH}$ ), 9.14 (s, $1 \mathrm{H}, \mathrm{OH}), 9.74(\mathrm{~s}, 1 \mathrm{H}, \mathrm{OH}) ;{ }^{13} \mathrm{C} \mathrm{NMR}\left(125 \mathrm{MHz}, \mathrm{DMSO}-d_{6}\right)$ $\delta 30.4,42.1,71.8,114.4,114.7,119.8,121.2,125.3,126.5$, $128.0,128.7,130.4,138.9,139.4,139.5,155.6,159.0$, 165.6; HRMS (ESI-TOF-MS) $m / z$, calcd. for $\mathrm{C}_{22} \mathrm{H}_{21} \mathrm{~N}_{2} \mathrm{O}_{2}$ $[\mathrm{M}+\mathrm{H}]^{+}:$345.1598, found: 345.1575 .

\section{2,7-Dimethyl-2,4-diphenyl-2,3-dihydro-1 $\mathrm{H}$-1,5-benzo-} diazepine (3d)

Yellow solid; mp 96-98 ${ }^{\circ} \mathrm{C}$; IR (KBr) $\bar{v} / \mathrm{cm}^{-1} 3281$, 3055, 2968, 2916, 1612, 1570, 1445, 1329; ${ }^{1} \mathrm{H}$ NMR $\left(400 \mathrm{MHz}, \mathrm{CDCl}_{3}\right) \delta 1.77\left(\mathrm{~s}, 3 \mathrm{H}, \mathrm{CH}_{3}\right), 2.35$ (s, 3H, $\left.\mathrm{ArCH}_{3}\right)$, 2.98 (dd, 1H, J 13.1, 9.3 Hz, $\mathrm{CH}_{2}$ ), 3.18 (dd, 1H, J 27.6, $13.1 \mathrm{~Hz}, \mathrm{CH}_{2}$ ), 3.63 (br s, $\left.1 \mathrm{H}, \mathrm{NH}\right), 6.65-6.96$ (m, 2H, Ar-H), 7.12-7.37 (m, 7H, 6Ph-H and 1H, Ar-H), 7.51-7.66 (m, 4H, Ph-H); $\left.{ }^{13} \mathrm{C} \mathrm{NMR} \mathrm{(100} \mathrm{MHz,} \mathrm{CDCl}_{3}\right) \delta 21.2,30.2$, 43.6, 73.0, 117.9, 121,0, 121.6, 122.5, 125.6, 127.2, 127.3, $128.2,128.4,128.7,129.1,129.9,133.2,136.8,137.4$, 138.2, 147.7, 167.2; HRMS (ESI-TOF-MS) $m / z$, calcd. for $\mathrm{C}_{23} \mathrm{H}_{23} \mathrm{~N}_{2}[\mathrm{M}+\mathrm{H}]^{+}:$327.1856, found: 327.1837 .

2,7-Dimethyl-2,4-bis(3-hydroxyphenyl)-2,3-dihydro$1 \mathrm{H}$-1,5-benzodiazepine (3e)

Yellow solid; mp 143-146 ${ }^{\circ} \mathrm{C}$; IR $(\mathrm{KBr}) \bar{v} / \mathrm{cm}^{-1} 3325$, 3250, 3040, 2963, 2914, 1603, 1582, 1452, 1323, 1254; ${ }^{1} \mathrm{H}$ NMR (400 MHz, DMSO- $\left.d_{6}\right) \delta 1.58\left(\mathrm{~s}, 3 \mathrm{H}, \mathrm{CH}_{3}\right), 2.25$ (s, 3H, $\left.\mathrm{ArCH}_{3}\right), 2.79$ (d, 1H, J $\left.13.6 \mathrm{~Hz}, \mathrm{CH}_{2}\right), 3.17$ (d, 1H, $J 13.6 \mathrm{~Hz}, \mathrm{CH}_{2}$ ), 5.58 (br s, $\left.1 \mathrm{H}, \mathrm{NH}\right), 6.50-6.54(\mathrm{~m}, 1 \mathrm{H}$, Ar-H), 6.65 (dd, 1H, J 8.0, 1.5 Hz, Ar-H), 6.71-6.77 (m, $1 \mathrm{H}, \mathrm{PhHOH}$ ), 6.81-6.85 (m, 1H, $\mathrm{PhHOH}), 6.89-7.10$ (m, $6 \mathrm{H}, 5 \mathrm{Ph} H \mathrm{OH}$ and $1 \mathrm{H}, \mathrm{Ar}-\mathrm{H}), 7.24-7.29$ (m, $1 \mathrm{H}, \mathrm{Ph} H \mathrm{OH})$, 9.17 (s, 1H, OH), 9.34 (s, 1H, OH); ${ }^{13} \mathrm{C}$ NMR (100 MHz, DMSO- $\left.d_{6}\right) \delta 20.8,30.7,42.8,70.3,112.9,113.2,116.1$, $116.6,118.0,120.2$, 120.9, 121.3, 126.7, 128.6, 128.8, 129.2, 135.3, 137.0, 139.5, 141.1, 149.9, 156.8, 164.3; HRMS (ESI-TOF-MS) $m / z$, calcd. for $\mathrm{C}_{23} \mathrm{H}_{23} \mathrm{~N}_{2} \mathrm{O}_{2}$ $[\mathrm{M}+\mathrm{H}]^{+}$: 359.1754, found: 359.1758 .

\section{2,7-Dimethyl-2,4-bis(4-hydroxyphenyl)-2,3-dihydro-}

\section{$1 \mathrm{H}-1,5$ benzodiazepine (3f)}

Yellow solid; mp 214-216 ${ }^{\circ} \mathrm{C}$; IR (KBr) $\bar{v} / \mathrm{cm}^{-1} 3335$, 3227, 3030, 2961, 2922, 1611, 1589, 1447, 1329, 1246; ${ }^{1} \mathrm{H}$ NMR (500 MHz, DMSO- $\left.d_{6}\right) \delta 1.57$ (s, 3H, $\left.\mathrm{CH}_{3}\right), 2.23$ (s, 3H, $\left.\mathrm{ArCH}_{3}\right), 2.75\left(\mathrm{~d}, 1 \mathrm{H}, J 13.4 \mathrm{~Hz}, \mathrm{CH}_{2}\right), 3.06(\mathrm{~d}, 1 \mathrm{H}$, $J 13.4 \mathrm{~Hz}, \mathrm{CH}_{2}$ ), 5.26 (br s, $\left.1 \mathrm{H}, \mathrm{NH}\right), 6.69-6.57$ (m, 5H, $4 \mathrm{PhHOH}$ and 1H, Ar-H), 6.77 (s, 1H, Ar-H), 6.95 (d, 1H, J 7.9 Hz, Ar-H), 7.34 (d, 2H, J 8.7 Hz, PhHOH), 7.56 (d, 2H, J 8.8 Hz, PhHOH), 9.13 (s, 1H, OH), 9.70 (s, 1H, OH);
${ }^{13} \mathrm{C}$ NMR $\left(125 \mathrm{MHz}, \mathrm{DMSO}-d_{6}\right) \delta 20.7,30.5,42.3,71.0$, $114.4,114.6,120.6,121.2$, 126.6, 128.3, 128.6, 130.7, 134.4, 136.6, 138.8, 139.3, 155.6, 158.8, 164.7; HRMS (ESI-TOF-MS) $m / z$, calcd. for $\mathrm{C}_{23} \mathrm{H}_{23} \mathrm{~N}_{2} \mathrm{O}_{2}[\mathrm{M}+\mathrm{H}]^{+}$: 359.1754, found: 359.1749 .

Antioxidant activities

DPPH scavenging activity

The evaluation of the antioxidant activity by the free radical sequestration method was measured by means of hydrogen donation using the stable radical 2,2-diphenyl1-picrylhydrazyl (DPPH). ${ }^{39}$ Measurements were performed in triplicate and inhibition activities were calculated based on the percentage of DPPH removal. An analogue of vitamin $\mathrm{E}\left(\right.$ Trolox $\left.^{\circledR}\right)$ and butylated hydroxytoluene (BHT) were used as standards. The DPPH solution without the compounds served as the control. The percentage DPPH radical-scavenging activity $(\%)$ was calculated according to the equation 1 :

DPPH radical-scavenging activity $(\%)=[(\mathrm{Ac}-\mathrm{As}) /(\mathrm{Ac})] \times$ 100

where Ac denotes the absorbance of the control (all reagents except the sample) and As denotes the absorbance of the sample. $\mathrm{IC}_{50}$ (effective concentration of the compound to eliminate $50 \%$ of the initial concentration of free radicals) of DPPH was calculated based on the linear regression of the percentage of remaining DPPH against the sample concentration.

\section{ABTS scavenging activity}

Antioxidant activity by the ABTS (2,2'-azinobis(3-ethylbenzothiazoline-6-sulfonic acid)) assay was based on the generation of the cationic chromophore radical obtained from the oxidation of ABTS by potassium persulfate. ${ }^{40}$ Measurements were performed in triplicate and inhibition activities were calculated based on the percentage of ABTS removed. An analogue of vitamin E $\left(\right.$ Trolox $^{\circledR}$ ) and BHT were used as standards. The percentage ABTS scavenging activity (\%) was calculated according to the equation 2 :

\section{ABTS scavenging activity $(\%)=[(\mathrm{Ac}-\mathrm{As}) /(\mathrm{Ac})] \times$} 100

$\mathrm{IC}_{50}$ of ABTS was calculated based on the linear regression of the percentage of remaining ABTS against the sample concentration. 
Total antioxidant capacity (TAC)

Total antioxidant capacity was determined by phosphomolybdenum method. ${ }^{41}$ The assay was based on the reduction of molybdenum ${ }^{+6}$ to molybdenum ${ }^{+5}$ by the sample and subsequent formation of a greenish phosphate/molybdenum ${ }^{+5}$ complex. Tubes containing the samples and reagents (Sigma-Aldrich, São Paulo, Brazil) (0.6 mol L $\mathrm{m}^{-1}$ sulfuric acid, $28 \mathrm{mmol} \mathrm{L}^{-1}$ sodium phosphate and $4 \mathrm{mmol} \mathrm{L}^{-1}$ ammonium molybdate) were incubated at $100{ }^{\circ} \mathrm{C}$ for $90 \mathrm{~min}$. Subsequently, the absorbances of each solution were measured at $695 \mathrm{~nm}$ against a blank. Ascorbic acid and BHT were used as references. The percentage of total antioxidant capacity (\%) was calculated according to the equation 3 :

Total antioxidant capacity $(\%)=[(\mathrm{Ac}-\mathrm{As}) /(\mathrm{Ac})] \times$ 100

$\mathrm{IC}_{50}$ of total antioxidant capacity was calculated based on the linear regression activity against the sample concentration.

\section{Antifungal activity assay}

Strains

The microorganisms used in the test were Sporothrix brasiliensis UFPE121, Sporothrix brasiliensis UFPE145, Sporothrix brasiliensis UFPE230 and Sporothrix schenckii UFPE289 provided by Department of Antibiotics of the Federal University of Pernambuco.

Determination of minimum inhibitory concentration (MIC) and minimal fungicidal concentrations (MFC)

The broth microdilution susceptibility assay followed Clinical Laboratory Standards Institute (CLSI) protocol M60. ${ }^{42}$ It was used 96-well flat bottom plates to carry this assay out. The compounds were solubilized in DMSO and diluted in the culture medium used in the assay, reducing the end concentration of solvent to $1 \%$. The compounds, at 2048, 1024, 512, 256, 128, 64, 32, 16, 8, 4, 2 and $1 \mu \mathrm{g} \mathrm{mL}^{-1}$ were added in RPMI-1640 (Roswell Park Memorial Institute, Sigma-Aldrich, São Paulo, Brazil) medium, buffered with morpholinopropanesulfonic acid (MOPS, $0.165 \mathrm{~mol} \mathrm{~L}^{-1}$, Sigma-Aldrich, São Paulo, Brazil), by adding yeast suspension, approximately $5 \times 10^{2}$ colony forming unit (CFU) $\mathrm{mL}^{-1}$. The samples were incubated at $30{ }^{\circ} \mathrm{C}$ for $24 \mathrm{~h}$. The resazurin solution $(0.01 \%)$ was used as indicator by color change visualization: any change in color from purple to pink was recorded as yeast growth. The lowest concentration, in which no color change occurred, was taken as minimum inhibitory concentration
(MIC). Subsequently, $10 \mu \mathrm{L}$ of each well were seeded on plates containing Sabouraud dextrose agar medium and incubated for $24 \mathrm{~h}$ at $30{ }^{\circ} \mathrm{C}$ to determine the minimum fungicidal concentration (MFC). Fluconazole was used as standard drug. Each trial in this experiment was performed in triplicate.

\section{In silico ADME studies}

ADME properties of compounds $\mathbf{3 a - 3} \mathbf{3}$ were assessed using online Molinspiration ${ }^{43}$ and OSIRIS Property Explorer ${ }^{44}$ programs. Among the physicochemical parameters calculated and evaluated were molecular weight (MW), lipophilicity (cLog P), number of hydrogen bond donors (nHBD) and number of hydrogen bond acceptors (nHBA), aqueous solubility (Log $\mathrm{S}$ ), the number of rotatable connections (Rot bond), the topological polar surface area (TPSA) and the percentage of intestinal absorption (ABS, in \%), which was estimated according to the equation $4 .{ }^{45}$

$$
\operatorname{ABS}(\%)=109-0.345 \times \text { TPSA }
$$

\section{Statistical analysis}

Results were expressed as mean values \pm standard deviation of three independent determinations. Statistical analysis was done with GraphPad Prism ${ }^{\circledR}$, version 5.0. ${ }^{46}$ The data were analyzed using analysis of variance (ANOVA), followed by Tukey's post-hoc test $(p \leq 0.05)$.

\section{Results and Discussion}

\section{Chemistry}

The preparation of benzodiazepine derivatives of interest (3a-3f) was performed based on an adaptation of a synthetic strategy already reported in the literature. ${ }^{24}$ Although the cyclocondensation reaction of $o$-phenylenediamine and ketone using acid catalyst is carried out under mild conditions as room temperature and solvent-free, its use and effectiveness is limited only to reactions with liquid ketones, which play both the reagent and solvent roles in the reaction medium. However, in this work was necessary to use a solvent because the target compounds are mainly derived from solid ketones. Thus, the synthesis of 2-methyl-2,4-diphenyl2,3-dihydro- $1 H$-1,5-benzodiazepine (3a) was performed as a model for temperature and solvents effects. It was observed that dielectric constant and polarity of solvents as well as temperature have a critical effect on the 
product yield. Solvents evaluated in this study included acetonitrile $(\mathrm{MeCN})$, methanol $(\mathrm{MeOH})$, ethanol $(\mathrm{EtOH})$, dimethylformamide (DMF) and DMSO. Initially, the reaction time of $15 \mathrm{~h}$ was defined for all tests based on the synthesis of $\mathbf{3 a}$ in ethanol at room temperature. This initial experiment gave the desired benzodiazepine in $78 \%$ isolated yield. So, the parameters reaction indicated in Table 2 were useful to identify the optimal experimental conditions that promoted the best yield of the product.

Table 2. Isolated yield of 2-methyl-2,4-diphenyl-2,3-dihydro$1 \mathrm{H}$-1,5-benzodiazepine obtained from experiments carried out using different solvents and temperatures after $15 \mathrm{~h}$

\begin{tabular}{lcccc}
\hline entry No. & Solvent & Temperature $/{ }^{\circ} \mathrm{C}$ & time $/ \mathrm{h}$ & Yield $^{\mathrm{a}} / \%$ \\
\hline 1 & $\mathrm{MeOH}$ & $\mathrm{RT}$ & 15 & 85 \\
2 & $\mathrm{MeOH}$ & reflux (65) & 15 & 54 \\
3 & $\mathrm{EtOH}$ & $\mathrm{RT}$ & 15 & 78 \\
4 & $\mathrm{EtOH}$ & reflux (78) & 15 & 51 \\
5 & $\mathrm{CH}_{3} \mathrm{CN}$ & $\mathrm{RT}$ & 15 & 45 \\
6 & $\mathrm{CH}_{3} \mathrm{CN}$ & reflux (82) & 15 & 36 \\
7 & $\mathrm{DMF}$ & $\mathrm{RT}$ & 15 & 29 \\
8 & $\mathrm{DMF}$ & reflux (100) & 15 & $\mathrm{NC}$ \\
9 & $\mathrm{DMSO}$ & $\mathrm{RT}$ & 15 & 17 \\
10 & $\mathrm{DMSO}$ & reflux (100) & 15 & $\mathrm{NC}$ \\
\hline
\end{tabular}

aIsolated yield. MeOH: methanol; RT: room temperature; EtOH: ethanol; $\mathrm{CH}_{3} \mathrm{CN}$ : acetonitrile; DMF: dimethylformamide; NC: not converted; DMSO: dimethyl sulfoxide.

Optimization of experimental conditions provided information about which factor was most important for higher yield of 3a. A maximum yield of $85 \%$ was observed using methanol as solvent and at room temperature. The formation of 1,5-benzodiazepines occurred in all experiments carried out at room temperature. In addition, yields were higher than those obtained with increased temperature. Perhaps it is interesting to highlight the possibility of side reactions leading to the formation of co-products (evidenced by TLC) at reflux temperature.

With respect to the influence of the solvent employed, significantly higher yields of product were observed both from the use of methanol and ethanol (Table 2, entries 1 and 3). The better performance of these polar protic solvents can be attributed to the ability to form hydrogen bonds, which probably confer higher stability of the conjugate base of TFA (improvement of catalytic activity) and of the transition state, leading, thus, to the increase of the yield in relation to the polar aprotic solvents (MeCN, DMF and DMSO). Therefore, the solvent and temperature were crucial for the formation of $\mathbf{3 a}$, which had its structure characterized by HRESIMS, FTIR, ${ }^{1} \mathrm{H}$ and ${ }^{13} \mathrm{C}$ NMR analysis. The HRESIMS mass spectrum gave a peak of $[\mathrm{M}+\mathrm{H}]^{+}$in $\mathrm{m} / z 313.17$ corresponding to the formation of the desired product $\left(\mathrm{C}_{22} \mathrm{H}_{20} \mathrm{~N}_{2}\right)$. The IR spectrum revealed characteristic bands at 1329, 1445 and 1595, 1632, 2920 and 2972, 3061 and $3277 \mathrm{~cm}^{-1}$ which can be attributed to $\mathrm{C}-\mathrm{N}, \mathrm{C}=\mathrm{C}, \mathrm{C}=\mathrm{N}, \mathrm{sp}^{3} \mathrm{C}-\mathrm{H}, \mathrm{sp}^{2} \mathrm{C}-\mathrm{H}$ and $\mathrm{N}-\mathrm{H}$ stretching vibrations, respectively. All NMR data are consistent with the structure of benzodiazepine. ${ }^{1} \mathrm{H}$ NMR spectrum showed the signals corresponding to the methyl hydrogens at $1.77 \mathrm{ppm}(\mathrm{s}, 3 \mathrm{H})$, to the methylene at 2.99 ppm $(\mathrm{d}, 1 \mathrm{H}, J 13.2 \mathrm{~Hz})$ and $3.17 \mathrm{ppm}(\mathrm{d}, 1 \mathrm{H}, J 13.2 \mathrm{~Hz})$, to the amine hydrogen at $3.56 \mathrm{ppm}(\mathrm{s}, 1 \mathrm{H})$, in addition to signals related to aromatic hydrogens at $6.86-7.63 \mathrm{ppm}$. In the ${ }^{13} \mathrm{C}$ NMR spectrum, the signals of quaternary carbons corresponding to the $\mathrm{CN}$ and $\mathrm{C}=\mathrm{N}$ bonds were observed at 73.89 and $168.24 \mathrm{ppm}$, respectively, as well as the signals belonging to the nucleus benzodiazepine, clearly indicating the formation of the desired product.

In order to investigate the performance of methanol and ethanol in a more general process, we decided to perform the synthesis of benzodiazepines (3b-3f) from benzene-1,2-diamine, 4-methylbenzene-1,2-diamine and 3- and 4-hydroxyacetophenone. As a result, the derivatives of interest were obtained in good to excellent yields for both reaction models (Table 1). It is worth to cite that the hydroxylated benzodiazepines $\mathbf{3 b}, \mathbf{3 e}$ and $\mathbf{3} \mathbf{f}$ are novel compounds, as far as we know, they were not reported previously. No significant differences were observed between the yields of the target hydroxylated compounds as regard to the solvent employed. But the reaction yield was increased until $16 \%$ with the use of hydroxyl substituents on the starting materials. Both solvents promoted the obtaining of novel hydroxybenzodiazepines $(\mathbf{3 b}, \mathbf{3 e}$ and $\mathbf{3 f})$ in high yields, in the range of $91-95 \%$. However, reactions carried out in methanol were faster than those corresponding reactions carried out in ethanol. The structures of the synthesized products (3b-3f) were confirmed by IR, ${ }^{1} \mathrm{H}$ NMR, ${ }^{13} \mathrm{C}$ NMR, HRESIMS and melting point.

Furthermore, slightly higher yields and shorter reaction times were achieved when the hydroxyl group is in meta position of hydroxyacetophenone, thus showing an effect of the position of the substituent. These variations are probably related to the fact that the hydroxy group causes a greater decrease in the electrophilic character of carbonyl group when it occupies the para position. This is why electron delocalization results in stable carbonyl carbon, that is, less susceptible to attack by nucleophile.

The similar percentage yields of compounds containing or not methyl group attached to ring of diamine indicated that there was no increase in nucleophilicity of starting 


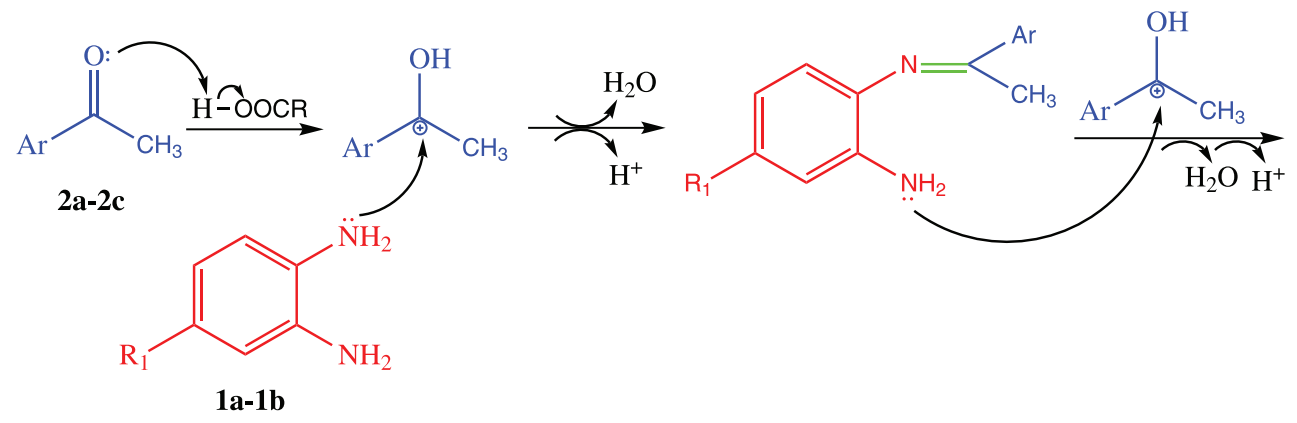<smiles>CC1(C)CC(Br)=Nc2cc(Br)ccc2N1</smiles>

3a-3f
Intramolecular imine enamine cyclization

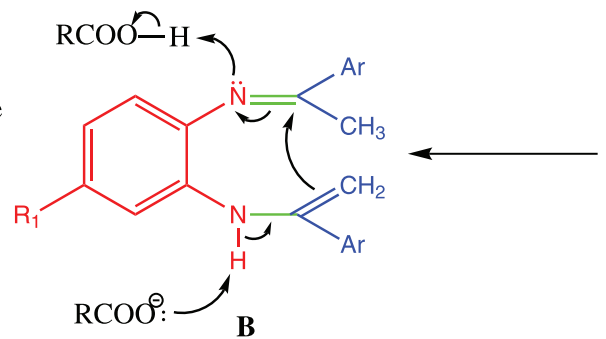

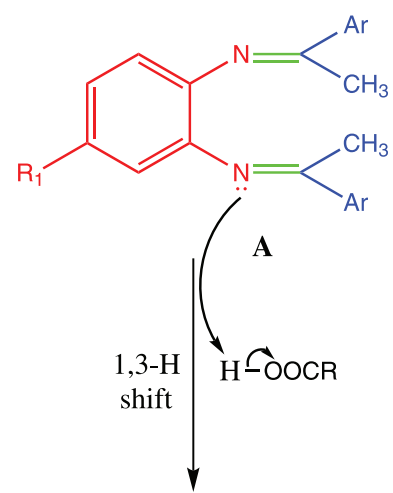

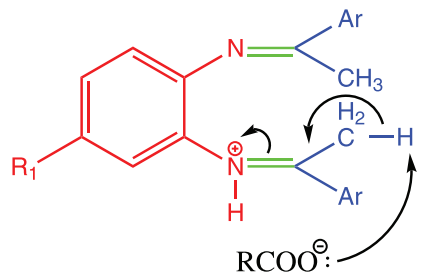

Scheme 2. Mechanistic proposal for the synthesis of 1,5-benzodiazepines (3a-3f).

material promoted by alkyl substitution, that is, a weak electron donor group did not affect the cyclocondensation catalyzed by TFA.

Based on previous studies, ${ }^{24,26}$ a reaction mechanism was proposed for the formation of the 1,5-benzodiazepines of interest, as shown in Scheme 2. Initially, the organoacid increases the electrophilicity of carbonyl carbon of the acetophenone through the protonation of its oxygen, which facilitates the nucleophilic attack of $o$-phenylenediamine resulting in the intermediate diimine $\mathbf{A}$. Then, from two acid-base steps promoted by a catalytic amount of Brønsted acid, a 1,3-H shift from the methyl group to the nitrogen of the imine occurs to form the intermediate enamine $\mathbf{B}$, which cyclizes providing the ring of seven members of the 1,5-benzodiazepines 3a-3f.

\section{Antioxidant activity}

The antioxidant activity of the 1,5-benzodiazepines (3a-3f) was evaluated by spectrophotometric assay. Namely, the scavenging of stable radical DPPH; ABTS and through the determination of TAC by the phosphomolybdenum method, using as standards Trolox, BHT and ascorbic acid. The results are expressed in terms of $\mathrm{IC}_{50}$ values (in $\mu \mathrm{g} \mathrm{mL}-1$ and $\mathrm{mmol} \mathrm{L}^{-1}$ ) and are summarized in Table 3.

In general, comparing the six benzodiazepines in spectrophotometric assay, $\mathbf{3 c}$ and $\mathbf{3 f}$ exhibited less $\mathrm{IC}_{50}$, so, more effective in scavenging of free radicals. It is worth mentioning that $\mathbf{3 f}$ derivative has not yet been published. The antioxidant activity of these derivatives was lower than that of the Trolox and BHT standards in the DPPH

Table 3. Antioxidant activities of the target compounds 3a-3f

\begin{tabular}{|c|c|c|c|c|c|c|}
\hline \multirow{3}{*}{ Compound } & \multicolumn{6}{|c|}{$\mathrm{IC}_{50}$} \\
\hline & \multicolumn{2}{|c|}{ DPPH } & \multicolumn{2}{|c|}{ ABTS } & \multicolumn{2}{|c|}{ TAC } \\
\hline & $\mu \mathrm{g} \mathrm{mL^{-1 }}$ & $\mathrm{mmol} \mathrm{L}^{-1}$ & $\mu \mathrm{g} \mathrm{mL} L^{-1}$ & $\mathrm{mmol} \mathrm{L}^{-1}$ & $\mu \mathrm{g} \mathrm{mL}^{-1}$ & $\mathrm{mmol} \mathrm{L}^{-1}$ \\
\hline $3 \mathbf{a}$ & $4961.0 \pm 0.03$ & 15.88 & $9812.3 \pm 0.05$ & 31.41 & $1625.34 \pm 0.01$ & 5.20 \\
\hline $3 \mathbf{b}$ & $1700.0 \pm 0.04$ & 4.94 & $3628.1 \pm 0.23$ & 10.53 & $1132.19 \pm 0.02$ & 3.29 \\
\hline $3 c$ & $604.2 \pm 0.17$ & 1.75 & $1248.6 \pm 0.19$ & 3.63 & $586.28 \pm 0.03$ & 1.70 \\
\hline 3d & $4776.0 \pm 0.01$ & 14.63 & $9239.2 \pm 0.13$ & 28.30 & $1425.91 \pm 0.02$ & 4.37 \\
\hline $3 e$ & $1598.3 \pm 0.23$ & 4.46 & $3123.5 \pm 0.93$ & 8.71 & $968.21 \pm 0.30$ & 2.70 \\
\hline $3 f$ & $411.0 \pm 0.38$ & 1.15 & $928.9 \pm 0.02$ & 2.59 & $495.14 \pm 0.24$ & 1.38 \\
\hline Trolox & $47.04 \pm 0.03$ & 0.19 & $214.3 \pm 0.05$ & 0.86 & NT & NT \\
\hline BHT & $157.32 \pm 0.02$ & 0.71 & $327.42 \pm 0.23$ & 1.49 & $772.14 \pm 0.11$ & 3.50 \\
\hline AA & NT & NT & NT & NT & $500.00 \pm 0.05$ & 2.84 \\
\hline
\end{tabular}

Values described in mean \pm standard deviation $(\mathrm{n}=3)$. $\mathrm{IC}_{50}$ : effective concentration of the compound to eliminate $50 \%$ of the initial concentration of free radicals; DPPH: radical 2,2-diphenyl-1-picrylhydrazyl; ABTS: radical 2,2'-azino-bis(3-ethylbenzothiazoline-6-sulfonic acid); TAC: total antioxidant capacity; NT: not tested; BHT: butylated hydroxytoluene; AA: ascorbic acid. 
and ABTS assays, but higher than that of the BHT and ascorbic acid (AA) standards in the TAC assay. Despite the variety $\mathrm{IC}_{50}$ values in the adopted methodologies, these results give us information that could be related to the antioxidant potential activities of benzodiazepines. Therefore, it was observed that the presence and position of the hydroxyl group influenced on antioxidant activity these compounds. It is worth noting that the hydroxylated benzodiazepines ( $\mathbf{3} \mathbf{c}$ and $\mathbf{3 f}$ ) with hydroxyl group in para position donated hydrogen radical $\left(\mathrm{H}^{\circ}\right)$ better, and therefore decreased the amount of free radicals more efficiently. Although hydroxyl group in meta position also donates $\mathrm{H}^{\circ}$, these differences in the $\mathrm{IC}_{50}$ values could be explained by less significant contributions from each of the resonance forms from hydroxylated benzodiazepines (3b and $\mathbf{3 e}$ ) radicals. These arguments could also be extended to the phenoxy radical (less reactive) which is more easily formed than the radical resulting from the cleavage of the $\mathrm{NH}$ bond present in the diazepine nucleus. Additionally, the presence of the methyl group (weak electron donor) in $\mathrm{R}_{1}$ contributes to the antioxidant activity, which corroborates the significant increase on the inhibition of radical free exhibited by compound $\mathbf{3 f}$ compared to the non-methylated 3c derivative.

\section{Antifungal activity}

The MIC and MFC values of benzodiazepines (3a-3f) evaluated against four strains of two important pathogenic species of the genus Sporothrix are shown in Table 4. The in vitro antifungal activities of these compounds were compared with fluconazole as a reference quality control.

The compound $\mathbf{3 f}$ exhibited a strong antifungal activity against all fungal strains tested with MIC ranging from 45 to $89 \mu \mathrm{mol} \mathrm{L}-1$ and MFC ranging from 89 to $179 \mu \mathrm{mol} \mathrm{L}^{-1}$, which was superior to other compounds and the reference drug fluconazole. This means that antifungal activity was dependent on the structure of benzodiazepines. For example, the compound $\mathbf{3 f}$ exhibited superior activity against the four fungal strains (MICs range 45-89 $\mu \mathrm{mol} \mathrm{L}^{-1}$ ) compared with their analogous 3c (MICs range 186-743 $\mu \mathrm{mol} \mathrm{L}^{-1}$ ), which are non-methylated correspondents. Furthermore, the presence of the hydroxyl group promoted the potentiation of the fungicidal action in relation to the non-hydroxylated derivatives 3a and 3d. Despite the $m$-hydroxylated compound 3e showing lower inhibitory action against the S. bras. (I) and S. bras. (II) strains, when observing their MIC and MFC values against the S. bras. (III) and S. schenckii strains, it could be noted the positive effect of the methyl and hydroxy groups in improving the inhibitory action of synthesized benzodiazepines.

It is possible that the substituents effects observed for the benzodiazepine's antifungal activity are due to the increase in lipophilicity promoted by the presence of methyl group, which provides more permeability in the fungal cell membrane allowing a more effective action of these compounds. Whilst hydroxyl groups improving activity can be related to the hydrogen bonding between these groups and water molecules in the fungal cells, corroborating to the increase of efficiency of the agent against the fungus.

In silico studies of the Lipinski's parameters, as well as the aqueous solubility ( $\log S)$, the number of rotatable bonds (Rot bond), the polar topological surface area (TPSA) and the percentage of human intestinal absorption (\% ABS), are shown in Table 5. The results of this theoretical approach indicated that all benzodiazepines derivatives fully comply with the Rule of Five. That is, Lipinski's parameters describe that these compounds possess molecular characteristics that satisfy the desirable profile for a drug administered orally. According to Lipinski, for a drug to have good permeability in biological membranes and good intestinal absorption it must have $\mathrm{MW} \leq 500$,

Table 4. Values of minimum inhibitory concentration (MIC) and minimum fungicidal concentration (MFC) of benzodiazepines

\begin{tabular}{|c|c|c|c|c|c|c|c|c|}
\hline \multirow[b]{2}{*}{ Compound } & \multicolumn{2}{|c|}{ S. bras. (I) } & \multicolumn{2}{|c|}{ S. bras. (II) } & \multicolumn{2}{|c|}{ S. bras. (III) } & \multicolumn{2}{|c|}{ S. schenckii } \\
\hline & $\begin{array}{c}\mathrm{MIC} / \\
\left(\mu \mathrm{mol} \mathrm{L}{ }^{-1}\right)\end{array}$ & $\begin{array}{c}\mathrm{MFC} / \\
\left(\mu \mathrm{mol} \mathrm{L}{ }^{-1}\right)\end{array}$ & $\begin{array}{c}\mathrm{MIC} / \\
\left(\mu \mathrm{mol} \mathrm{L}{ }^{-1}\right)\end{array}$ & $\begin{array}{c}\text { MFC / } \\
\left.(\mu \mathrm{mol} \mathrm{L})^{-1}\right)\end{array}$ & $\begin{array}{c}\mathrm{MIC} / \\
\left(\mu \mathrm{mol} \mathrm{L}{ }^{-1}\right)\end{array}$ & $\begin{array}{c}\mathrm{MFC} / \\
\left(\mu \mathrm{mol} \mathrm{L}{ }^{-1}\right)\end{array}$ & $\begin{array}{c}\mathrm{MIC} / \\
\left(\mu \mathrm{mol} \mathrm{L}{ }^{-1}\right)\end{array}$ & $\begin{array}{c}\mathrm{MFC} / \\
\left(\mu \mathrm{mol} \mathrm{L}{ }^{-1}\right)\end{array}$ \\
\hline $3 a$ & 410 & 819 & 410 & 819 & 410 & 819 & 3278 & 6555 \\
\hline $3 \mathbf{b}$ & 372 & 743 & 372 & 743 & 372 & 743 & 1487 & 2973 \\
\hline $3 c$ & 186 & 372 & 186 & 372 & 186 & 372 & 743 & 1487 \\
\hline $3 d$ & 196 & 392 & 196 & 392 & 392 & 784 & 3137 & 6274 \\
\hline $3 e$ & 357 & 714 & 714 & 1428 & 179 & 357 & 357 & 714 \\
\hline $3 f$ & 45 & 89 & 45 & 89 & 45 & 89 & 89 & 179 \\
\hline FLU & 52 & 104 & 104 & 209 & 52 & 104 & 209 & 418 \\
\hline
\end{tabular}

S. bras. (I): Sporothrix brasiliensis (UFPE121); S. bras. (II): Sporothrix brasiliensis (UFPE145); S. bras. (III): Sporothrix brasiliensis (UFPE230); S. schenckii: Sporothrix schenckii (UFPE289); FLU: fluconazole. 
Table 5. Parameters values evaluated in in silico ADME (absorption, distribution, metabolism, and excretion) studies for benzodiazepines and itraconazole (ITCZ)

\begin{tabular}{|c|c|c|c|c|c|c|c|c|c|}
\hline \multirow{2}{*}{ Compound } & \multicolumn{4}{|c|}{ Lipinski's parameter } & \multirow{2}{*}{ Violation } & \multirow{2}{*}{$\log S^{b}$} & \multirow{2}{*}{ Rot bond ${ }^{a}$} & \multirow{2}{*}{ TPSA $^{\mathrm{b}}$} & \multirow{2}{*}{ ABS / \% } \\
\hline & $\mathrm{MW}^{\mathrm{a}}$ & $\mathrm{nHBD}^{\mathrm{a}}$ & nHBA $^{a}$ & $\operatorname{cLog} \mathrm{P}^{\mathrm{b}}$ & & & & & \\
\hline $3 \mathbf{a}$ & 312.42 & 1 & 2 & 4.50 & 0 & -5.20 & 2 & 24.39 & 100 \\
\hline $3 \mathbf{b}$ & 344.41 & 3 & 4 & 3.81 & 0 & -4.61 & 2 & 64.85 & 86.63 \\
\hline $3 c$ & 344.41 & 3 & 4 & 3.81 & 0 & -4.61 & 2 & 64.85 & 86.63 \\
\hline 3d & 326.44 & 1 & 2 & 4.85 & 0 & -5.55 & 2 & 24.39 & 100 \\
\hline $3 e$ & 358.44 & 3 & 4 & 4.15 & 0 & -4.95 & 2 & 64.85 & 86.63 \\
\hline $3 f$ & 358.44 & 3 & 4 & 4.15 & 0 & -4.95 & 2 & 64.85 & 86.63 \\
\hline ITCZ & 705.65 & 0 & 12 & 5.15 & 3 & -7.30 & 11 & 100.70 & 74.26 \\
\hline
\end{tabular}

${ }^{a}$ Molinspiration; 'O Osiris Property Explorer. MW: molecular weight $\leq 500$; nHBD: number hydrogen bond donors $\leq 5$; nHBA: number hydrogen bond acceptors $\leq 10$; lipophilicity (octanol-water partition coefficient, $\operatorname{cog} \mathrm{P}$ ) $\leq 5 ; \log \mathrm{S}$ aqueous solubility (between -1 and -5 ); Rot bond: rotatable bonds $\leq 10$; TPSA: topological polar surface area $\leq 140 \AA^{2}$; ABS: percentage of human intestinal absorption (ABS(\%) $=109-0.345 \times$ TPSA) $(>80 \%$ is high; $<25 \%$ is poor).

lipophilicity (octanol/water partition coefficient, $\operatorname{cLog} \mathrm{P}) \leq 5$, $\mathrm{nHBD} \leq 5$ and $\mathrm{nHBA} \leq 10 .{ }^{47}$

Additionally, contributing to the assessment of the oral bioavailability profile of benzodiazepines, it was observed that the presence of hydroxyls in $\mathrm{R}_{2}$ provided an increase in aqueous solubility ( $\log \mathrm{S})$. According to the $\log \mathrm{S}$ values, only hydroxylated derivatives (3b, 3c, 3e and $\mathbf{3 f}$ ) have aqueous solubility ( -4.61 to -4.95$)$ within the reference range ( -1 to -5$)$, which is common for about $85 \%$ of the drugs sold and reflects the balance between polarity and hydrophobicity necessary to guarantee acceptable aqueous solubility and cell permeability. ${ }^{48}$ The number of rotatable bonds equal to 2 for all compounds indicates that the synthesized benzodiazepines possess adequate flexibility to promote good permeability and absorption, which is within the reference range $(\leq 10) .{ }^{47}$ Regarding the TPSA of benzodiazepines, an important indicator of human intestinal absorption, we observed that all compounds exhibited values within the acceptable limit $\left(\leq 140 \AA^{2}\right) .{ }^{49}$ The calculated percentage of ABS of all benzodiazepine derivatives ranged value superior to $80 \%$, which suggest high human intestinal absorption for these compounds.

Thus, based on the results presented the hydroxylated derivatives have shown to possess a good profile of pharmacokinetic ADME properties, with emphasis on the unprecedented compound $\mathbf{3 f}$, which met all the criteria of oral bioavailability and presented the best performance in in vitro assays of antifungal and antioxidant activity, being, therefore, a potential drug candidate to be administered orally.

In a comparative analysis with the commercial antifungal drug itraconazole (ITCZ), drug of first choice in the treatment of sporotrichosis, it was observed that the synthesized benzodiazepines present a significantly higher solubility and permeability profile than itraconazole, which violates several requirements related to oral bioavailability. Among them, three requirements associated with Lipinski's parameters, namely, the molecular mass superior to 500, the number of hydrogen bond acceptors higher than 10 and the lipophilicity greater than 5 . Besides, it presented low aqueous solubility ( $\log \mathrm{S}=-7.30)$ and a high number of rotatable bonds $>10$. Although, topological polar surface value within the reference range indicated moderate intestinal absorption ( $\mathrm{ABS}=74.26 \%$ ). These results reinforce, therefore, the potential of clinical use of the novel derivative $\mathbf{3 f}$, as well as encouraging us to use the other compounds obtained as precursors in the production of other drug candidates.

\section{Conclusions}

Solvent effects studies have indicated that increased yields of 1,5-benzodiazepines can be obtained using methanol and ethanol as solvents. Regarding biological activities in in vitro assays, the hydroxylated benzodiazepines not only have presented high antifungal activity against all fungal strains evaluated, but they have also shown the best results regarding antioxidant and antifungal properties. Furthermore, in silico studies have suggested that these compounds possess better aqueous solubility and cell permeability profile compared to the antifungal itraconazole, meeting all oral bioavailability needs required for therapeutic use. Thus, it is worth emphasizing that the antifungal potential found against fungi of the Sporothrix schenckii complex of the novel 2,7-dimethyl-2,4-bis(4-hydroxyphenyl)-2,3-dihydro$1 H$-1,5-benzodiazepine (3f) inaugurates an unprecedented property for this class of compounds, opening important and innovative research paths. 


\section{Supplementary Information}

Supplementary data of compounds synthesized are available free of charge at http://jbcs.sbq.org.br as PDF file.

\section{Acknowledgments}

We thank the National Council for Scientific and Technological Development (CNPq) and National Council for the Improvement of Higher Education (CAPES) for financial support. We would also like to thank the Federal University of Paraíba (UFPB), Federal University of Pernambuco (UFPE) and Multi-User Characterization and Analysis Laboratory of UFPB for enabling the acquisition of ${ }^{1} \mathrm{H}$ NMR, ${ }^{13} \mathrm{C}$ NMR and HRESIMS spectra.

\section{Author Contributions}

Neide Queiroz was responsible for guiding and planning this research and for revising the manuscript; Elizeu C. Caiana was responsible for the synthesis of the compounds and for the studies in silico, as well as for the writing of the manuscript; Bruno O. de Veras was responsible for carrying out the experiments on antifungal and antioxidant activities; Antônia L. de Souza contributed with important suggestions for the development of the research and for the revision of the manuscript.

\section{References}

1. Jeganathan, M.; Pitchumani, K.; ACS Sustainable Chem. Eng. 2014, 2, 1169.

2. Yin, L.; Wang, L.; Tetrahedron Lett. 2016, 57, 5935.

3. Singh, R. K.; Sharma, S.; Kaur, A.; Saini, M.; Kumar, S.; Iran. J. Catal. 2016, 6, 1 .

4. Indalkar, K. S.; Patil, M. S.; Chaturbhuj, G. U.; Tetrahedron Lett. 2017, 58, 4496.

5. Wang, L.-Z.; Li, X.-Q.; An, Y.-S.; Org. Biomol. Chem. 2015, $13,5497$.

6. Jaafar, Z.; Chniti, S.; Sassi, A. B.; Dziri, H.; Marque, S.; Lecouvey, M.; Gharbi, R.; Msaddek, M.; J. Mol. Struct. 2019, $1195,689$.

7. Fruscella, P.; Sottocorno, M.; Di Braccio, M.; Diomede, L.; Piccardi, N.; Cagnotto, A.; Grossi, G.; Romano, M.; Mennini, T.; Roma, G.; Pharmacol. Res. 2001, 43, 445.

8. K, I. B.; Kumar, A.; Asian J. Pharm. Clin. Res. 2016, 9, 63.

9. Theodosis-Nobelos, P.; Papagiouvannis, G.; Kourounakis, P. N.; Rekka, E. A.; Molecules 2019, 24, 3277.

10. Neochoritis, C. G.; Tsoleridis, C. A.; Stephanidou-Stephanatou, J.; Kontogiorgis, C. A.; Hadjipavlou-Litina, D. J.; J. Med. Chem. 2010, 53, 8409 .
11. Ongone, T. N.; Achour, R.; El Ghoul, M.; El Ouasif, L.; El Jemli, M.; Chemlal, L.; Cherrah, Y.; Alaoui, K.; Zellou, A.; J. Chem. 2019, 2019, 9043570 .

12. Chen, Y.; Le, V.; Xu, X.; Shao, X.; Liu, J.; Li, Z.; Bioorg. Med. Chem. Lett. 2014, 24, 3948.

13. Verma, D.; Kumar, P.; Narasimhan, B.; Ramasamy, K.; Mani, V.; Mishra, R. K.; Majeed, A. B. A.; Arabian J. Chem. 2019. 12, 2882

14. Singh, R. K.; Prasad, D. N.; Bhardwaj, T. R.; J. Saudi Chem. Soc. 2017, 21, S86.

15. Thi, M. D. D.; Grant, M. H.; Mullen, A. B.; Tettey, J. N. A.; MacKay, S. P.; Clark, R. L.; J. Pharm. Pharmacol. 2009, 61, 399.

16. Insuasty, B.; Ramírez, J.; Becerra, D.; Echeverry, C.; Quiroga, J.; Abonia, R.; Robledo, S. M.; Vélez, I. D.; Upegui, Y.; Muñoz, J. A.; Ospina, V.; Nogueras, M.; Cobo, J.; Eur. J. Med. Chem. 2015, 93, 401.

17. Nyanguile, O.; Pauwels, F.; van de Broeck, W.; Boutton, C. W.; Quirynen, L.; Ivens, T.; van der Helm, L.; Vandercruyssen, G.; Mostmans, W.; Delouvroy, F.; Dehertogh, P.; Cummings, M. D.; Bonfanti, J. F.; Simmen, K. A.; Raboisson, P.; Antimicrob. Agents Chemother. 2008, 52, 4420.

18. Chander, S.; Tang, C.-R.; Al-Maqtari, H. M.; Jamalis, J.; Penta, A.; Hadda, T. B.; Sirat, H. M.; Zheng, Y.-T.; Sankaranarayanan, M.; Bioorg. Chem. 2017, 72, 74.

19. Madhav, J. V.; Rajitha, B.; Phosphorus, Sulfur Silicon Relat. Elem. 2008, 183, 2984.

20. Jampilek, J.; Molecules 2019, 24, 3839.

21. Taylor, A. P.; Robinson, R. P.; Fobian, Y. M.; Blakemore, D. C.; Jones, L. H.; Fadeyi, O.; Org. Biomol. Chem. 2016, 14, 6611.

22. Jamatia, R.; Gupta, A.; Dam, B.; Saha, M.; Pal, A. K.; Green Chem. 2017, 19, 1576.

23. Jamatia, R.; Saha, M.; Pal, A. K.; RSC Adv. 2014, 4, 12826.

24. Zhao, Y.; Sharma, S.; Huang, M.; Sandhar, A.; Singh, R. K.; Ma, Y.; Asian J. Chem. 2014, 26, 5116.

25. Bhatia, M. S.; Choudhari, P. B.; Ingale, K. B.; Zarekar, B. E.; Orient. J. Chem. 2008, 24, 147.

26. Amoozadeh, A.; Malmir, M.; Koukabi, N.; Otokesh, S.; J. Chem. Res. 2015, 39, 694.

27. Chatterjee, N. R.; Chandak, B. G.; Thube, S. S.; Kulkarnia, S. D.; Deshpande, A. D.; Int. J. Chem. Sci. 2009, 7, 805.

28. Mihailović, N.; Marković, V.; Matić, I. Z.; Stanisavljević, N. S.; Jovanović, Ž. S.; Trifunović, S.; Joksović, L.; RSC Adv. 2017, 7,8550 .

29. Lobo, V.; Patil, A.; Phatak, A.; Chandra, N.; Pharmacogn. Rev. 2010, 4, 118

30. Pisoschi, A. M.; Pop, A.; Eur. J. Med. Chem. 2015, 97, 55.

31. Neha, K.; Haider, M. R.; Pathak, A.; Yar, M. S.; Eur. J. Med. Chem. 2019, 178, 687.

32. Carrasco-Zuber, J. E.; Navarrete-Dechent, C.; Bonifaz, A.; Fich, F.; Vial-Letelier, V.; Berroeta-Mauriziano, D.; Actas DermoSifiliogr. 2016, 107, 806. 
33. Mahajan, V. K.; Dermatol. Res. Pract. 2014, 2014, 272376.

34. McCarty, T. P.; Pappas, P. G.; Curr. Fungal Infect. Rep. 2014, 8, 255 .

35. Sharkey-Mathis, P. K.; Kauffman, C. A.; Graybill, J. R.; Stevens, D. A.; Hostetler, J. S.; Cloud, G.; Dismukes, W. E.; Am. J. Med. 1993, 95, 279.

36. Ravi, V.; Vijay, K.; Ramu, E.; Ganapaty, S.; Rao, A. S.; Asian J. Chem. 2007, 19, 5435.

37. An, Y.-S.; Hao, Z.-F.; Zhang, X.-J.; Wang, L.-Z.; Chem. Biol. Drug Des. 2016, 88, 110.

38. Yan, A. In Applied Chemoinformatics: Achievements and Future Opportunities, $1^{\text {st }}$ ed.; Engel, T.; Gasteiger, J., eds.; Wiley-VCH Verlag GmbH \& Co. KgaA: Weinheim, Germany, 2018, ch. 6.9.

39. Kose, E. O.; Aktas, O.; Deniz, I. G.; Sarikurkcu, C.; J. Med. Plants Res. 2010, 4, 1698.

40. Re, R.; Pellegrini, N.; Proteggente, A.; Pannala, A.; Yang, M.; Rice-Evans, C.; Free Radical Biol. Med. 1999, 26, 1231.

41. Costa, L. S.; Fidelis, G. P.; Telles, C. B. S.; Dantas-Santos, N.; Camara, R. B. G.; Cordeiro, S. L.; Costa, M. S. S. P.; AlmeidaLima, J.; Melo-Silveira, R. F.; Oliveira, R. M.; Albuquerque, I. R. L.; Andrade, G. P. V.; Rocha, H. A. O.; Mar. Drugs 2011, 9 , 952.
42. Clinical Laboratory Standards Institute (CLSI); Performance Standards for Antifungal Susceptibility Testing of Yeasts, $1^{\text {st }} \mathrm{ed}$.; CLSI: Pennsylvania, USA, 2017.

43. Molinspiration - Calculation of Molecular Properties and Bioactivity Score; available at https://www.molinspiration.com/ cgi-bin/properties, accessed in October 2020.

44. Sander, T.; OSIRIS Property Explorer; Idorsia Pharmaceuticals Ltd., Switzerland, 2017.

45. Zhao, Y. H.; Abraham, M. H.; Le, J.; Hersey, A.; Luscombe, C. N.; Beck, G.; Sherborne, B.; Cooper, I.; Pharm. Res. 2002, 19, 1446.

46. Motulsky, H. J.; GraphPad Prism, v.5.0; GraphPad Software Inc., USA, 2007.

47. Lipinski, C. A.; Drug Discovery Today: Technol. 2004, 1, 337.

48. Jorgensen, W. L.; Duffy, E. M.; Adv. Drug Delivery Rev. 2002 , 54,355 .

49. Veber, D. F.; Johnson, S. R.; Cheng, H.-Y.; Smith, B. R.; Ward, K. W.; Kopple, K. D.; J. Med. Chem. 2002, 45, 2615.

Submitted: July 27, 2020

Published online: November 4, 2020 